九州大学学術情報リポジトリ

Kyushu University Institutional Repository

\title{
A Comparison Experiment of Two Types of Printed Circuit Board TDR Probes
}

Wang, We izhen

Laboratory of Forest Ecosystem Management, Division of Forest Ecosphere Management, Department of Forest and Forest Products Sciences, Graduate School of Bioresource and Bioenvironmental Sciences, Kyushu University

Kobayashi, Tetsuo

Laboratory of Applied Meteorology, Division of Regional Environment Science, Department of Bioproduction Environmental Science, Faculty of Agriculture, Graduate School, Kyushu University

Cho, Hiroyuki

Department of Agricultural Sciences, Saga University

Chikushi, Jiro

Biotron Institute, Kyushu University

https://doi.org/10.5109/24417

出版情報 : 九州大学大学院農学研究院紀要. 46 (1)，pp.15-21，2001-10-30. Kyushu University バージョン：

権利関係 : 
J. Fac. Agr., Kyushu Univ., 46 (1), 15-21 (2001)

\title{
A Comparison Experiment of Two Types of Printed Circuit Board TDR Probes
}

\author{
Weizhen WANG*, Tetsuo KOBAYASHI, Hiroyuki CHO** \\ and Jiro CHIKUSHI*** \\ Laboratory of Applied Meteorology, Division of Regional Environment Science, \\ Department of Bioproduction Environmental Science, Faculty of Agriculture, \\ Graduate School, Kyushu University, Fukuoka 812-8581, Japan \\ (Received June 29, 2001 and accepted July 11, 2001)
}

\begin{abstract}
An experiment designed to compare two types of printed circuit board TDR probes (PCBPs) was conducted using the Tottori-Dune sand. Although the material and design of the two types were almost the same, the results differed much between them. This suggests that the performance of PCBPS is highly sensitive to their probe material and/or layout of wave-guide. Furthermore, the sensitivity to soil wetness differed from each other and changed also with soil wetness itself. Therefore the probe that is suitable for the particular purpose should be selected in each application.
\end{abstract}

\section{INTRODUCTION}

Wang et al. (2000) made newly designed printed circuit board TDR probes (henceforth C-type PCBPs) and used them to measure the average water content over the top $5 \mathrm{~cm}$ of unvegetated soils in an arid area in the northwest of China. They compared the measurements taken with the C-type PCBP and those by the oven-dry method, and showed that this type of probe does a good job as the sensor to get the ground truth of surface wetness against remotely sensed data obtained with microwave techniques. Other kinds of PCBPs were produced and tested by Nissen et al. (1999) and concluded also that they were promising for obtaining small-scale TDR measurements of soil water.

One of the authors (H. Cho) got some pieces of another type of PCBP produced by Dr. Nissen (henceforth $\mathrm{N}$-type PCBP). Hence we carried out an indoor experiment to compare the results obtained with the two types of PCBPs when they were used to measure the average water content over the top $5 \mathrm{~cm}$ of the soil. This paper describes the experimental results, and discusses some differences between the two types and their characteristics.

\section{DESCRIPTIONS OF PCBPS}

The C-type PCBP was made of $15 \times 60 \mathrm{~mm}$ paper-phenol resin of $1.3 \mathrm{~mm}$ thickness

*** Biotron Institute, Kyushu University, Fukuoka 812-8581, Japan

** Department of Agricultural Sciences, Saga University, Saga 840-8502, Japan

* Laboratory of Forest Ecosystem Management, Division of Forest Ecosphere Management, Department of Forest and Forest Products Sciences, Graduate School of Bioresource and Bioenvironmental Sciences, Kyushu University Corresponding author (E-mail: kobayasi@agr.kyushu-u.ac.jp) 
with a copper cladding on one side. The two-wire serpentine wave-guide $158 \mathrm{~mm}$ long were produced by printing two parallel rods $0.7 \mathrm{~mm}$ wide at a $23-\mathrm{mm}$ spacing onto the copper cladding and etching away the metal outside of them (Fig. 1). The effective length (the soil layer thickness over which this probe measure the average wetness) was $50 \mathrm{~mm}$. On the other hand, the N-type PCBP was made of $12 \times 50 \mathrm{~mm}$ glass-epoxy resin of $1 \mathrm{~mm}$ thickness. The two-wire serpentine wave-guide $86 \mathrm{~mm}$ in length was produced with two parallel rods $0.5 \mathrm{~mm}$ in width at a $3.35 \mathrm{~mm}$ spacing in the copper cladding. Its effective length was $50 \mathrm{~mm}$. Their probe designs are shown in Fig.1 and important properties are given in Table 1.

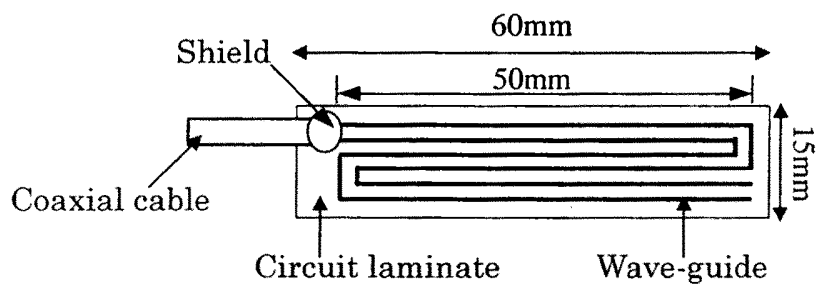

(a)

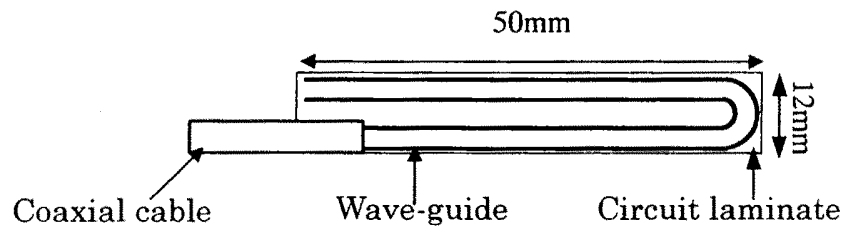

(b)

Fig. 1. Serpentine layouts of (a) C-type and (b) N-type probes.

Table 1. Properties of two types of PCBPs.

\begin{tabular}{lcc}
\hline & C-type & N-type \\
\hline Circuit board & paper-phenol & glass-epoxy \\
Dielectric thickness $(\mathrm{mm})$ & 1.3 & 1 \\
Thickness of cladding $(\mu \mathrm{m})$ & - & 35 \\
Wave-guide length $(\mathrm{mm})$ & 158 & 86 \\
Width of rods $(\mathrm{mm})$ & 0.7 & 0.4 \\
Spacing (mim) & 2.3 & 3.35 \\
Water absorption $(\%)$ & - & 0.35 \\
Dielectric constant & $4.6-5.5$ & 5.8 \\
\hline
\end{tabular}




\section{EXPERIMENT}

An indoor experiment to compare the two kinds of PCBPs was conducted using the Tottori-Dune sand, the physical properties of which are shown in Table 2. The sand was packed into containers, which were made of two 5-cm-long acrylic resin tubes of $10 \mathrm{~cm}$ inside diameter. The two tubes were joined end to end with adhesive, waterproof tape to be a cylinder $10 \mathrm{~cm}$ long. The bottom of the cylinder was made of wire netting, which was covered with a filter paper of $10 \mathrm{~cm}$ diameter before the air-dried sand was packed into it.

Table 2. Physical properties of the Tottori-Dune sand.

\begin{tabular}{rc}
\hline Particle size & by weight \\
\hline$>2 \mathrm{~mm}$ & $0 \%$ \\
$2.0 \sim 0.42 \mathrm{~mm}$ & $14.9 \%$ \\
$0.42 \sim 0.075 \mathrm{~mm}$ & $80.9 \%$ \\
$0.075 \sim 0.005 \mathrm{~mm}$ & $1.3 \%$ \\
$0.005>$ & $2.9 \%$ \\
& \\
Bulk density & $1.50 \mathrm{gcm}^{-3}$ \\
Porosity & 0.434 \\
\hline
\end{tabular}

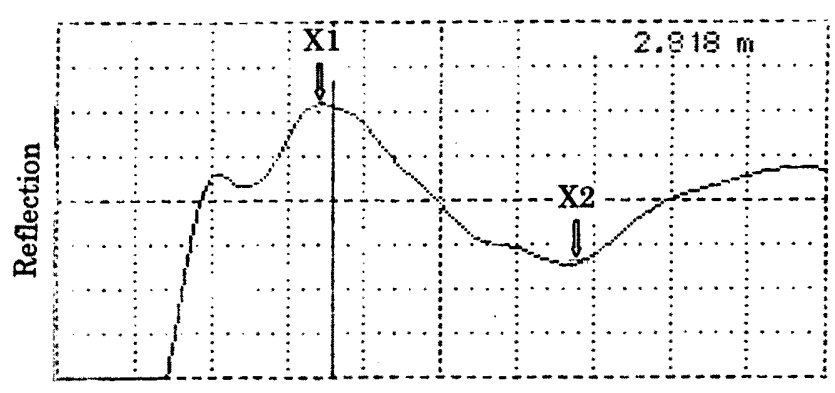

Distance(m)

(a)

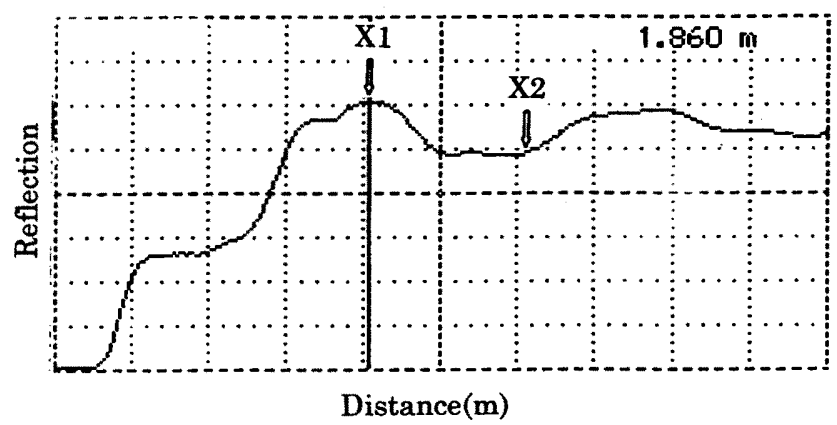

(b)

Fig. 2. Comparison of TDR oscilloscope traces of (a) C-type and (b) N-type probes. 
Four containers were constructed and one set of C-type and N-type probes was embedded vertically in each container to measure the average water content for the uppermost $5 \mathrm{~cm}$ of the sand, and water was poured on the surface until drainage from the bottom occurred. Once in several days measurements of the dielectric constant were made with Tektronix cable tester $1502 \mathrm{C}$ for one of the containers. After the measurement, a soil-sampling pipe $5 \mathrm{~cm}$ in length and $100 \mathrm{~cm}^{3}$ in volume was inserted from the surface into the container and a soil specimen was sampled from the top $5 \mathrm{~cm}$ of the profile and its water content was gravimetrically measured. These runs were made several times.

Figure 2 shows a comparison of TDR output traces measured using Tektronix 1502C, showing reflection as a function of equivalent cable distance, of the two types of PCBPs. These oscilloscope traces show similar waveforms for the two types, but the equivalent cable distance $(\mathrm{m})$ between the points $X_{1}$ and $X_{2}$ in Fig. 2 for the C-type probe is much longer than for the $\mathrm{N}$-type probe. The reason for this is that the length of wave-guide of $\mathrm{C}$-type probe is longer than of $\mathrm{N}$-type probe (Table 1). The apparent relative dielectric permittivity, or the dielectric constant $\left(K_{a}\right)$ of the medium of interest is calculated by

$$
K_{a}=\left[\left(X_{2}-X_{1}\right) / L V_{p}\right]^{2}
$$

where $L$ is the length of wave guide (m) and $V_{p}$ is the relative velocity of propagation (as usual set as $V_{p}=0.99$ ).

\section{RESULTS AND DISCUSSION}

Figure 3 shows the relationship between the dielectric constant measured with C-type PCBPS $\left(K_{a, P C B P-C}\right)$ and volumetric water content $\theta_{v}$. For the sake of brevity, hereafter, we shall use $K_{a}$ instead of $K_{a, P C B P-C}$ unless otherwise mentioned. The solid line shows the regression curve obtained by Wang et al. (2000). Our measurements made in this experiment were put together with those by Wang et al. (2000) because their material and method were the same as ours, which are denoted by open circle in Fig. 3. The dotted line describes the third-order polynomial regression equation that is fit to the whole data.

$$
K_{a, P C B P-C}=3.58+15.6 \theta_{v}+37.7 \theta_{v}^{2}+167.4 \theta_{v}^{3}
$$

The two regression curves are close together, which means that the experimental results are reliable. Figure 4 shows the relationship between the dielectric constant measured with N-type PCBPs $\left(K_{a, P C B P_{-N}}\right)$ and $\theta_{v}$. We shall use also $K_{a}$ instead of $K_{a, P C B P-N}$ unless otherwise mentioned. The regression equation is written

$$
K_{a, P C B P-N}=2.78+40.8 \theta_{v}-219.0 \theta_{r}{ }^{2}+553.7 \theta_{v}{ }^{3}
$$

The value of $K_{a, P C B P_{C} C}$ at any given value of $\theta_{v}$ is lager than that of $K_{a, P C B P-N}$. The dielectric constant measured with PCBPs $\left(K_{a, P C B P}\right)$ is regarded as the weighted mean of the laminate's value $\left(K_{a, L}\right)$ and the surrounding medium's value $\left(K_{a, m}\right)$ (Nissen et al., 1999).

$$
K_{a, P C B P}^{n}=w_{L}\left(K_{a, L}\right)^{n}+\left(1-w_{L}\right)\left(K_{a, m}\right)^{n}
$$

Since the value of $K_{a, L}$ of the $\mathrm{N}$-type probe is larger than of the C-type probe (Table 1), 


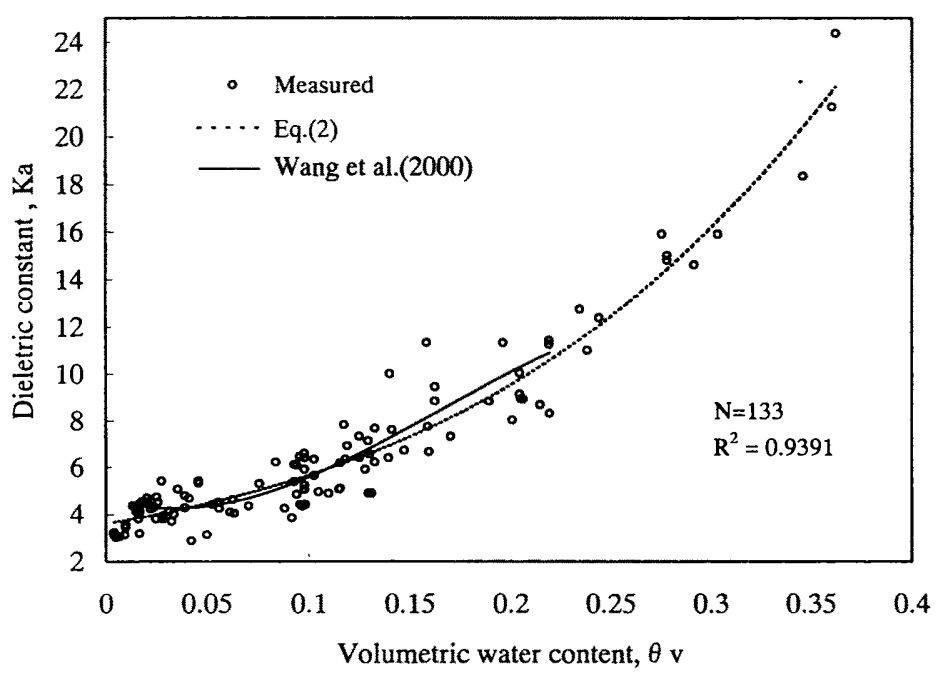

Fig. 3. Relationship between $K_{q}$ measured with C-type PCBPS and $\theta_{v}$ for the Tottori-Dune sand. The relationship obtained by Wang et al. $(2000)$ is also shown for reference.

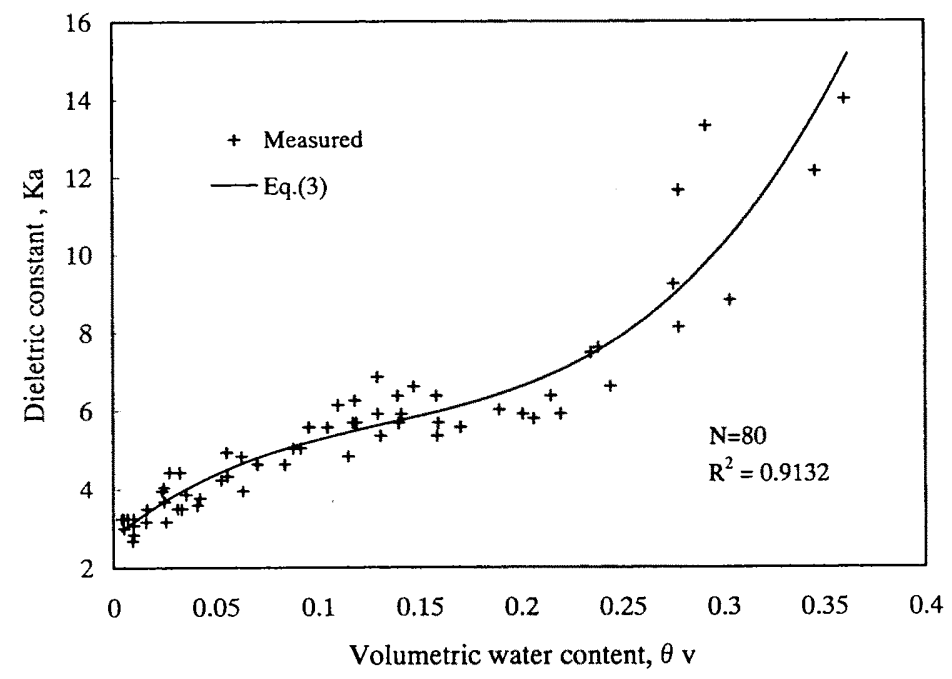

Fig. 4. Same as Fig. 3, but for $K_{n}$ measured with N-type PCBPs. 
the value of weighting factor $w_{L}$ for the $\mathrm{N}$-type probe must be smaller than for the C-type probe, especially when $\theta_{v}$ is nearly equal to zero. The value of $w_{L}$ depends on the degree of contact between the probe and the soil, and hence it seems reasonable to conclude that the contact of the N-type probe with the soil is not so good as the C-type probe.

One of the reasons for this seems to be a delicate difference in structure between them; that is, the $\mathrm{N}$-type probe has the wave-guide with a short length ( $86 \mathrm{~mm}$ ) and its ratio between rod width and rod spacing is small (0.12) compared to those of the C-type probe ( $158 \mathrm{~mm}$ and 0.3 , respectively). In this experiment, these probes were embedded vertically in the top $5 \mathrm{~cm}$ of the soil, and soil wetness changed with depth in the upper layers. Therefore, there was also a difference in experimental conditions between them; that is, the end of wave-guide of the $\mathrm{N}$-type probe was near the soil surface where the soil was drier than below, while the end of wave-guide of the C-type probe was located at the lowest point where the soil was wetter than above. However, we are not sure whether or not this difference can be another reason for the result above.

In reality, we estimate $\theta_{v}$ from the measurement of $K_{a}$ using the regression equation of $\theta_{v}$ on $K_{a}$. The regression equations for the two probes are as follows.

$$
\begin{array}{ll}
\theta_{v}=-0.09+3.54 \times 10^{-2} K_{a}-0.69 \times 10^{-3} K_{a}^{2}-0.18 \times 10^{-6} K_{a}^{3} & : \text { C-type } \\
\theta_{v}=-0.19+6.47 \times 10^{-2} K_{a}-1.25 \times 10^{-3} K_{a}^{2}-0.44 \times 10^{-4} K_{a}^{3} & : \text { N-type }
\end{array}
$$

These lines are shown in Fig. 5 together with the line given by Topp et al. (1980):

$$
\theta_{v}=-0.05+2.92 \times 10^{-2} K_{a}-0.55 \times 10^{-3} K_{a}^{2}+0.43 \times 10^{-5} K_{a}^{3}
$$

As can be seen, the line for the $\mathrm{N}$-type probe differs from the other two lines.

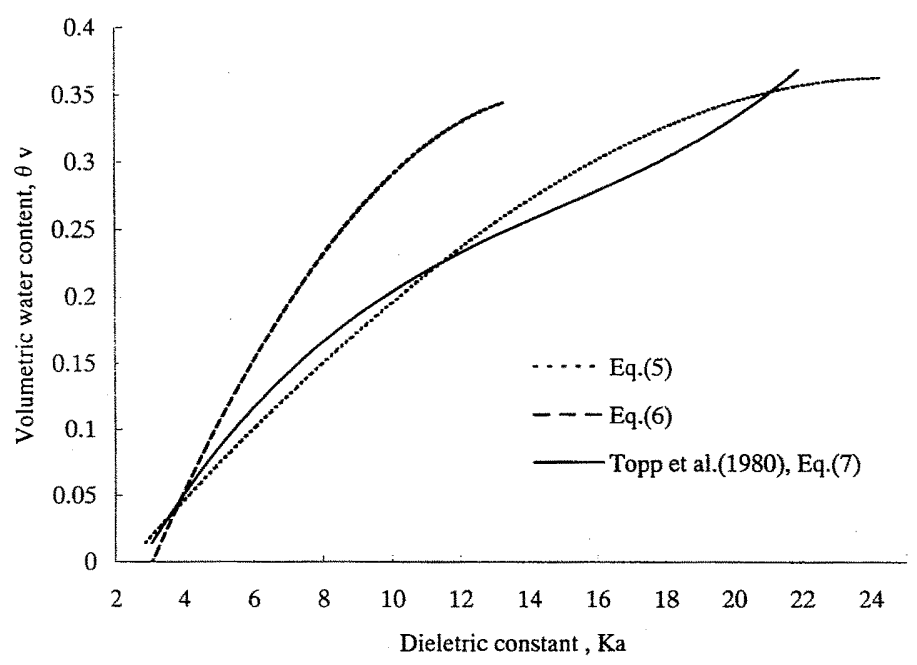

Fig. 5. Regression lines of $\theta_{r}$ on $K_{\mathfrak{a}}$ for the Tottori-Dune sands. 


\section{CONCLUDING REMARKS}

The performance of two types of printed circuit board TDR probes (PCBPs) was tested using the Tottori-Desert sand. Although their material and design are almost the same, the results of one type differed considerably from the other. This suggests that the performance is highly sensitive to probe material and/or layout of wave-guide.

The sensitivity of the PCBP changes with soil wetness. For example, the sensitivity of the $\mathrm{N}$-type probe is rather good at volumetric water contents smaller than 0.1 , however it becomes rather bad in the range of 0.1 to 0.25 (Fig. 4). Therefore, the PCBP that is suitable for the particular purpose should be selected in each application.

\section{ACKNOWLEDGEMENTS}

The authors are indebts to Prof. S. Ogawa of Kyushu University for his support in this study. They wish also to thank Dr. H. H. Nissen of Aalborg University, Denmark, for offering them his PCBPs used in this experiment.

\section{REFERENCES}

Nissen, H. H., P. Moldrup, T. Olesen and P. Raskmark 1999 Printed circuit board time domain reflectometry probe: Measurements of soil water content. Soil Sci., 164(7):454-466

Topp, G. C., J. L. Davis and A. P. Annan 1980 Electromagnetic determination of soil water content: Measurements in coaxial transmission lines. Water Resour. Res., 16(3):574-582

Wang, W., T. Kobayashi and J. Chikushi 2000 : Measuring the layer-average volumetric water content in the uppermost $5 \mathrm{~cm}$ of soil using printed circuit board TDR probes. J. Fac. Agr. Kyushu Univ., $\mathbf{4 5}(1): 277-287$. 